\title{
molecules
}

ISSN 1420-3049

www.mdpi.com/journal/molecules

Article

\section{Antioxidant Activity of Extracts of Momordica Foetida Schumach. et Thonn.}

Rosaria Acquaviva ${ }^{1}$, Claudia Di Giacomo ${ }^{1, *}$, Luca Vanella ${ }^{1}$, Rosa Santangelo ${ }^{1}$, Valeria Sorrenti ${ }^{1}$, Ignazio Barbagallo ${ }^{1}$, Carlo Genovese ${ }^{2}$, Silvana Mastrojeni ${ }^{2}$, Salvatore Ragusa ${ }^{3}$ and Liliana Iauk ${ }^{2}$

1 Department of Drug Science - Biochemistry Section, University of Catania, Catania 95125, Italy

2 Department of Bio-Medical Sciences, Section of Microbiology, University of Catania, Catania 95125, Italy

3 Department of Health Sciences, University "Magna Graecia” of Catanzaro, Catanzaro 88100, Italy

* Author to home correspondence should be addressed; E-Mail: cdigiaco@unict.it;

Tel.: +39-095-738-4115; Fax: +39-095-738-4220.

Received: 31 December 2012; in revised form: 16 January 2013 / Accepted: 6 March 2013 /

Published: 13 March 2013

\begin{abstract}
Momordica foetida Schumach. et Thonn. (Cucurbitaceae) is a perennial climbing herb with tendrils, found in swampy areas in Central Uganda. Antidiabetic and antilipogenic activities were reported for some Momordica species, however the mechanism of action is still unknown. Oxidative stress may represent an important pathogenic mechanism in obesity-associated metabolic syndrome. The present study evaluated free radical scavenging capacity of different concentrations of aqueous, methanolic and dichloromethane leaf extracts of Momordica foetida Schumach. et Thonn. and the ability of these extracts to inhibit in vitro plasma lipid peroxidation; in addition, healthy human adipose mesenchymal stem cell cultures were used in order to test the hypothesis that these extracts may affect adipocyte differentiation. Results obtained in this study suggested that aqueous extract might be useful in preventing metabolic syndrome.
\end{abstract}

Keywords: Momordica foetida Schumach. et Thonn.; antioxidant activity; adipogenic differentiation 


\section{Introduction}

Momordica foetida Schumach. et Thonn. (Cucurbitaceae) is a medicinal plant, widely distributed in tropical Africa, south and west tropical Africa, that has both male and female flowers [1]. It is a perennial climbing herb with tendrils, the flowers are cream colored, often with a reddish or orange centre and its characteristic fruit is bright orange with prickles. M. foetida Schumach. et Thonn. is found in swampy areas in Central Uganda. Drinking of aqueous leaf extracts of the plant to treat malaria is reported in East and Central Africa [2]. Other medicinal uses of extracts of this plant include the treatment of hypertension, peptic ulcers, diabetes mellitus, and as a purgative [2,3]. Curcubitane triterpenoids, polyphenolic compounds, have been isolated from leaf extracts, and alkaloids and glycosides from whole plant extracts. Antidiabetic and antilipogenic activities were also reported for some Momordica species, however the mechanism of action is still unknown [4].

Several studies have correlated obesity with high levels of lipid peroxidation and decreased antioxidant levels [5-7]. Oxidative stress, which results when free-radical formation exceeds protective antioxidant mechanisms or the later are compromised, has become a focus of intense interest in most biomedical disciplines and many types of clinical research; increasing evidence from research show that oxidative stress is associated with the pathogenesis of obesity and it has been demonstrated that in vitro pre-adipocyte proliferation and differentiation can be controlled by redox metabolism [8-17] suggesting that reactive oxygen species (ROS) are involved in adipocyte differentiation.

In the present study the free radical scavenging capacity of different concentrations of aqueous, methanolic and dichloromethane leaf extracts of Momordica foetida Schumach. et Thonn. was evaluated by in vitro assays; moreover the ability of these extracts to inhibit plasma lipid peroxidation in vitro was also evaluated. In addition, human adipose mesenchymal stem cell (hMSC) cultures were used in order to test the hypothesis that these extracts may also affect adipocyte differentiation.

\section{Results and Discussion}

Table 1 reports the total phenolic and flavonoid contents of the three different extracts. Aqueous extract resulted richer in phenolic and flavonoid compounds compared to methanol and dichloromethane extracts.

Table 1. Total polyphenols and total flavonoids in three different extracts of leaves of Momordica foetida Schumach. et Thonn.

\begin{tabular}{ccc}
\hline Extract & Total Phenolic content $\boldsymbol{\mu M}$ Gallic acid & Total Flavonoid Content $\boldsymbol{\mu M}$ Catechin \\
\hline Aqueous & $50 \pm 0.05$ & $2.80 \pm 0.20$ \\
Methanolic & $15 \pm 0.01$ & $4 \pm 0.09$ \\
Dichloromethane & $5 \pm 0.01$ & $0.3 \pm 0.03$ \\
\hline
\end{tabular}

Consistent with their different polyphenol contents, scavenger activities of the three extracts differed, depending on the type of extract. The aqueous extract has proven the most effective scavenger, with an effect that, at $175 \mu \mathrm{g} / \mathrm{mL}$, was comparable with $80 \mathrm{mU}$ superoxide dismutase (SOD). The methanolic and dichloromethane extracts exhibited scavenger activities lower than aqueous; the less active was dichloromethane extract (Figure 1). 
Figure 1. Scavenger effect of extracts of $M$. foetida Schumach. et Thonn. on superoxide anion; results are expressed as percentage of inhibition of NADH oxidation (rate of superoxide anion production was $4 \mathrm{nmol} / \mathrm{min}$ ). Each value represents the mean $\pm \mathrm{SD}$ of five experimental determinations. $* p<0.001 v s$. the same concentration of the aqueous extract.

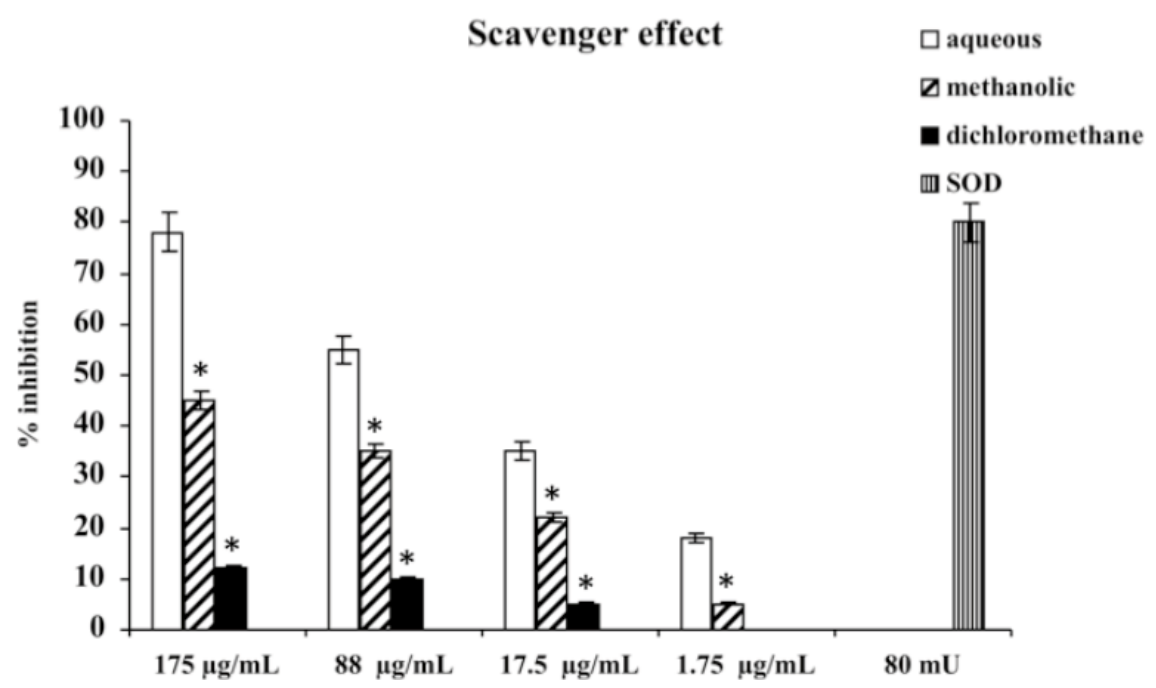

Based on polyphenol contents and our results regarding scavenger activities of the three extracts, aqueous extract was chosen for subsequent experiments. Figure 2 shows results obtained by incubating plasma of a healthy donor in the presence of different concentrations of aqueous extract of $M$. foetida Schumach. et Thonn.; as seen, the presence of the extract during incubation of plasma caused a considerable and dose-dependent inhibition of plasma lipid hydroperoxide (LOOH) formation.

Figure 2. Effect of aqueous extract of M. foetida Schumach. et Thonn. on LOOH production in plasma; results are expressed as percentage of inhibition of LOOH formation with respect to the same sample incubated in absence of the extract. Each value represents the mean $\pm \mathrm{SD}$ of five experimental determinations.

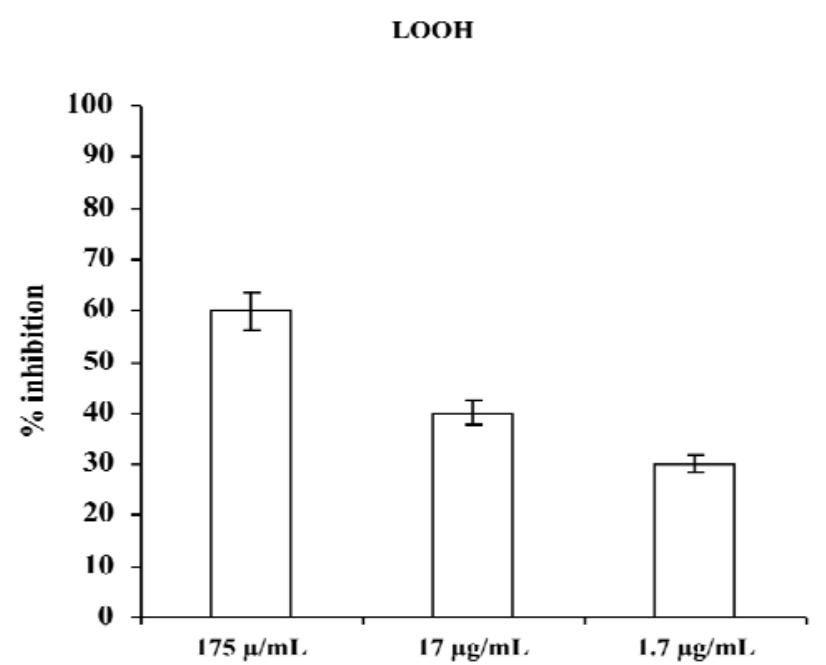

These results demonstrated that antioxidants present in aqueous extract of leaves of $M$. foetida Schumach. et Thonn. are able to counteract radical chain reactions, preventing peroxidative damage of plasma lipids beyond the action of antioxidants naturally present in plasma. 
We also tested the hypothesis that the aqueous extract of $M$. foetida Schumach. et Thonn. might affect adipogenic differentiation of human adipose mesenchimal cells. These cells are capable of differentiating into many different types of phenotypes, including osteoblasts, myocytes, chondrocytes and adipocytes in vivo and in vitro [18-20]. The directed differentiation of MSC can be performed in vitro using the appropriate media and the adipogenic differentiation is confirmed by specific staining.

As seen in Figure 3, our results demonstrated an increase in adipogenesis and accumulation of lipid droplets in cultured human adipose tissue-derived mesenchimal cells compared to the same cells treated with the aqueous extract of $M$. foetida Schumach. et Thonn.

Figure 3. Effect of aqueous extract of leaves of $M$. foetida Schumach. et Thonn. on adipogenesis of hMSCs as measured by Oil Red O staining. Each value represents the mean \pm S.D. of five experimental determinations. ${ }^{*} p<0.001 v s$. control.

Oil Red 0 staining

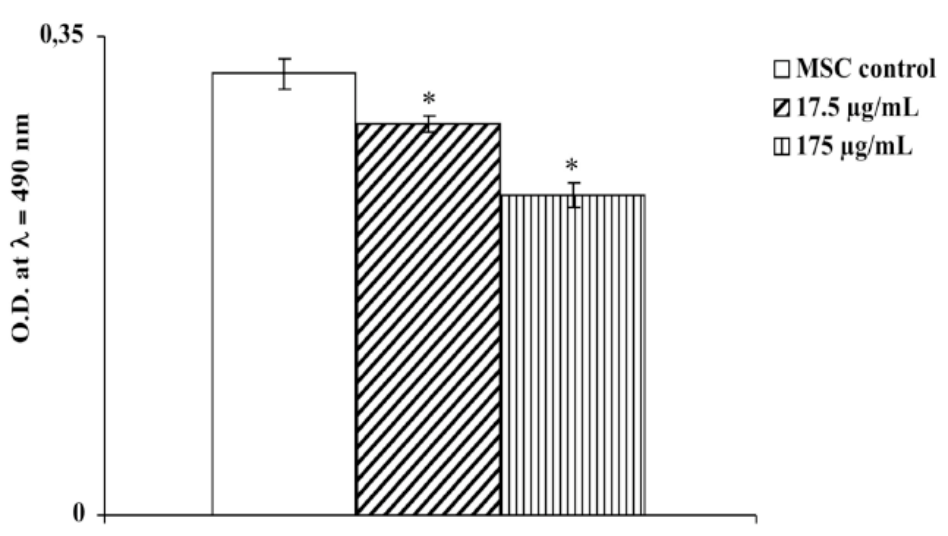

It has been suggested that increased levels of reactive oxygen species (ROS), with consequent shifting of the intracellular redox status vs. oxidant conditions, promote adipogenesis $[9,11,13,15]$. Then, the decreased adipogenesis observed in hMSC cultured in the presence of aqueous extract of M. foetida Schumach. et Thonn., might be ascribed to its free radical scavenger effects; in order to verify this hypothesis, ROS were determined using a fluorescent probe, 2',7'-dichlorofluorescein diacetate (DCFH-DA). After diffusion into the cells, this probe is deacetylated by cellular esterases to a non-fluorescent compound which is oxidized by ROS into 2',7'-dichlorofluorescein (DCF), a highly fluorescent compound whose fluorescence intensity is proportional to the levels of ROS [21].

As reported in Figure 4, the exposure for $72 \mathrm{~h}$ of hMSCs to $17.5 \mu \mathrm{g} / \mathrm{mL}$ or $175 \mu \mathrm{g} / \mathrm{mL}$ aqueous extract of $M$. foetida Schumach. et Thonn. resulted in a significant decrease in ROS. These data confirm the results obtained using in vitro cell-free systems and further support our hypothesis that antiadipogenic activity of $M$. foetida Schumach. et Thonn. might be due to a decrease in intracellular ROS levels. 
Figure 4. Determination of ROS by DCFH method in cultured hMSC: effect of aqueous extract of $M$. foetida Schumach. et Thonn. Each value represents the mean \pm S.D. of five experimental determinations. ${ }^{*} p<0.001 v s$. the same cells cultured in the absence of plant extract (control). Results are expressed as Fluorescence Intensity (F.I.) $\times 1 \times 10^{6} / \mathrm{mg}$ prot).

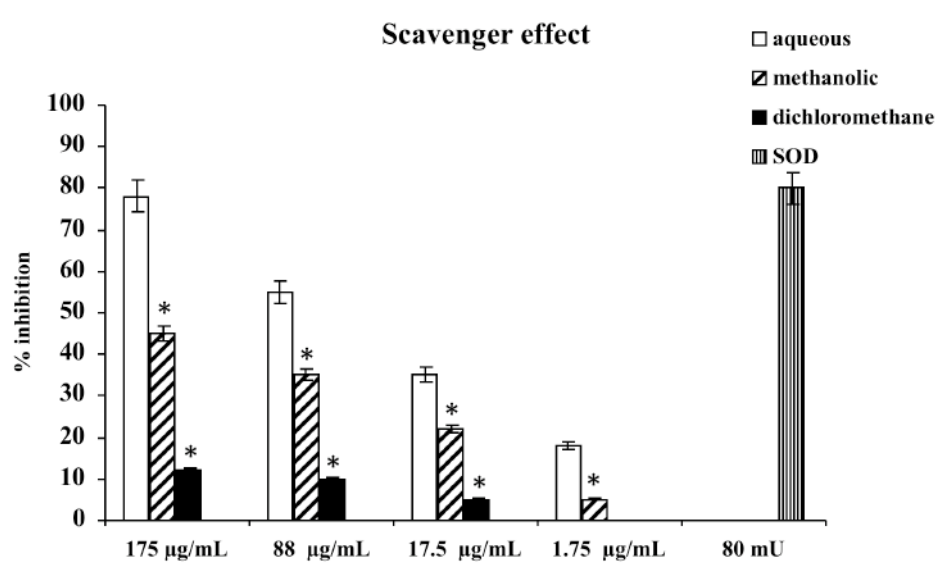

\section{Experimental}

\subsection{Chemicals}

Water, methanol and dichloromethane used for the extractions were of analytical grade and were purchased from Merck S.P.A. (Milan, Italy); all the other solvents, chemicals and reference compounds were purchased from Sigma-Aldrich (Milan, Italy).

\subsection{Plant Collection and Preparation of Extracts}

The leaves of Momordica foetida Schumach. et Thonn. were collected in August 2010 in the Eastern Democratic Republic of Congo and kindly provided by Sister Kavira Muhyama, Diocese of Butembo-Beni, Bunyuka. A voucher specimen of the plant was deposited in the herbarium of Department of Health Sciences, University "Magna Graecia" of Catanzaro. Aqueous, methanolic and dichloromethane extracts were obtained by maceration of each powdered plant sample $(2.5 \mathrm{~g})$ in water, methanol and dichloromethane $(50 \mathrm{~mL})$, respectively, for $24 \mathrm{~h}$ under constant shaking at room temperature. The extracts were filtered and evaporated to dryness under reduced pressure with a rotatory evaporator.

\subsection{Total Phenolic and Flavonoid Content}

The concentration of total phenolic compounds was determined spectrophotometrically, using the Folin-Ciocalteu total phenols procedure, as described by Ballard et al. [22], with modifications. Known amounts of gallic acid were used to prepare the standard curve. Appropriately diluted test extracts $(0.1 \mathrm{~mL})$ and the gallic acid standard solutions $(0.1 \mathrm{~mL})$ were transferred to $15 \mathrm{~mL}$ test tubes. Folin-Ciocalteu reagent $(3.0 \mathrm{~mL}, 0.2 \mathrm{~N})$ was added to each test tube and the contents mixed using a vortex mixer. After $1 \mathrm{~min}, 9.0 \%(\mathrm{w} / \mathrm{v}) \mathrm{Na}_{2} \mathrm{CO}_{3}$ in water $(2.0 \mathrm{~mL})$ was added and the solution was mixed. Absorbance was determined at $\lambda=765 \mathrm{~nm}$. The concentration of total phenolic compounds in the extracts was determined comparing the absorbance between the extract samples and the gallic acid 
standard solutions. All samples were determined in triplicate. Total phenolic content was expressed as $\mu \mathrm{mol}$ gallic acid/L \pm S.D.

The flavonoid concentration was measured using a colorimetric assay [23], with modifications. A standard curve of cathechin was used for quantification. Briefly, aqueous, methanolic and dichloromethane extracts $(25 \mathrm{~mL})$ and/or cathechin standard solutions were added to $\mathrm{H}_{2} \mathrm{O}(100 \mathrm{~mL})$. At time zero, $5 \% \mathrm{NaNO}_{2}(7.5 \mathrm{~mL})$ was added; after $5 \mathrm{~min}, 10 \% \mathrm{AlCl}_{3}(7.5 \mathrm{~mL})$ was added and at 6 min, $1 \mathrm{M} \mathrm{NaOH}(50 \mathrm{~mL})$ was added. Each reaction mixture was then immediately diluted with $\mathrm{H}_{2} \mathrm{O}$ $(60 \mathrm{~mL})$ and mixed. Absorbances of the mixtures upon the development of pink color were determined a $\lambda=510 \mathrm{~nm}$ relative to a prepared blank. The total flavonoid contents of the samples are expressed as $\mu \mathrm{mol}$ catechin/L. Each result represents the mean \pm S.D. of three experimental determinations.

\subsection{Scavenger Effect on Superoxide Anion}

Superoxide anion was generated in vitro as described by Acquaviva et al. [24]. A total volume of

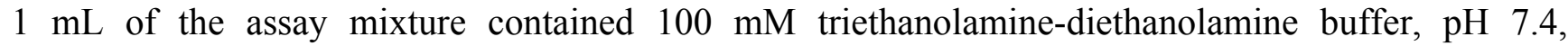
$3 \mathrm{mM}$ NADH, $25 \mathrm{mM} / 12.5 \mathrm{mM}$ EDTA/ $\mathrm{MnCl}_{2}, 10 \mathrm{mM} \beta$-mercaptoethanol; samples contained different concentrations (1.75-17.5-88-175 $\mu \mathrm{g} / \mathrm{mL})$ of the three (aqueous, methanolic and dichloromethane) extracts of leaves of $M$. foetida Schumach. et Thonn. After 20 min incubation at $25{ }^{\circ} \mathrm{C}$, the decrease in absorbance at $\lambda=340 \mathrm{~nm}$ was measured. Results are expressed as percentage of inhibition of NADH oxidation. SOD $(80 \mathrm{mU})$ was used as reference compound. Each result represents the mean \pm S.D. of five experimental determinations.

\subsection{Determination of Lipid Hydroperoxide Levels in the Plasma of a Healthy Donor}

Heparinized venous blood of a healthy volunteer donor, who agreed to take part in the study and gave his written consent, was collected after overnight fasting. Plasma was separated by centrifugation at $800 \mathrm{~g}$ for $20 \mathrm{~min}$. Plasmatic lipid hydroperoxide levels were evaluated by oxidation of $\mathrm{Fe}^{2+}$ to $\mathrm{Fe}^{3+}$ in the presence of xylenol orange at $\lambda=560 \mathrm{~nm}$ [25]. Heparinized venous blood was collected after overnight fasting; plasma was separated by centrifugation at $800 \mathrm{~g}$ for $20 \mathrm{~min}$. Plasma aliquots $(500 \mu \mathrm{L})$ were diluted 1:1 with oxygenated PBS and incubated at $37{ }^{\circ} \mathrm{C}$ for $2 \mathrm{~h}$ with or without different concentrations of the aqueous extracts $(1.75-17.5-175 \mu \mathrm{g} / \mathrm{mL})$ in a total volume of $1 \mathrm{~mL}$. Results are expressed as percentage of inhibition respect to control (plasma incubated in absence of test compounds) and represent the mean \pm S.D. of five experimental determinations.

\subsection{Isolation and Adipogenic Differentiation of Human Adipose MSCs}

Adipose tissue sample was obtained from a patient underwent abdominal plastic surgery (male, 25 years old); the subject provided his written consent before inclusion in the study, which was conducted according to the guidelines of the Ethical Commitee of the University of Catania, Italy. Adipose tissue sample was removed under sterile conditions, washed in PBS, minced, and digested with $1 \mathrm{mg} / \mathrm{mL}$ collagenase type $\mathrm{I}$ in $0.1 \% \mathrm{BSA}$ for $1 \mathrm{~h}$ at $37^{\circ} \mathrm{C}$ in a shaking water bath. The pellet was collected by centrifugation at $650 \mathrm{~g}$ for $10 \mathrm{~min}$ and then treated with red blood cell lysis buffer (155 $\mathrm{mM} \mathrm{NH}_{4} \mathrm{Cl}, 10 \mathrm{mM} \mathrm{KHCO}_{3}$ and $0.1 \mathrm{mM}$ EDTA) for $10 \mathrm{~min}$ at room temperature. After 
centrifugation the cellular pellet was filtered through a $100-\mu \mathrm{m}$ mesh filter to remove debris. The filtrate was centrifuged, and the obtained stromal vascular fraction was plated onto $100 \mathrm{~mm}$ cell culture dishes in complete culture medium (DMEM containing 20\% fetal bovine serum, $100 \mu \mathrm{g} / \mathrm{mL}$ streptomycin, $100 \mathrm{U} / \mathrm{mL}$ penicillin, $2 \mathrm{mM}$ L-glutamine, and $1 \mu \mathrm{g} / \mathrm{mL}$ amphotericin-B). Cells were cultured at $37{ }^{\circ} \mathrm{C}$ in humidified atmosphere with $5 \% \mathrm{CO}_{2}$. After $24 \mathrm{~h}$, non-adherent cells were removed, and adherent cells were washed twice with PBS. Confluent cells were trypsinized and expanded in T75 flasks (passage 1). A confluent and homogeneous fibroblast-like cell population was obtained after 2-3 weeks of culture. For all the experiments, only cells at early passages were used. At $50-60 \%$ confluence the medium was replaced with adipogenic medium, and the cells were cultured for an additional 15 days. The adipogenic media consisted of complete culture medium supplemented with DMEM-high glucose $(4.5 \mathrm{~g} / \mathrm{L}), 10 \%(\mathrm{w} / \mathrm{v}) \mathrm{FBS}, 10 \mathrm{mg} / \mathrm{mL}$ insulin, $0.5 \mathrm{mM}$ dexamethasone and $0.1 \mathrm{mM}$ indomethacin. Media were changed every 2 days.

\subsection{Oil Red O Staining and Lipid Droplet Size}

Oil Red $\mathrm{O}$ staining is an assay performed to stain induced adipogenic cultures to detect mature adipocytes. The histological mechanism of the staining of lipids is invariably a function of the physical properties of the dye being more soluble in the lipid than in the vehicular solvent. The polyazo group of dyes include the oil red series, the Sudan red series and the Sudan blacks.

For Oil Red O staining, $0.21 \%$ Oil Red O in 100\% isopropanol was used. Briefly, MSC-derived adipocytes, after 15 days, were fixed in 10\% formaldehyde, washed in Oil-red $\mathrm{O}$ for 10 min, rinsed with $60 \%$ isopropanol, and the Oil red $\mathrm{O}$ eluted by adding 100\% isopropanol for $10 \mathrm{~min}$ and Optical Density measured at $\lambda=490 \mathrm{~nm}$ in a microplate reader (Synergy HT multi-mode microplate reader, BioTek, Milan, Italy). Results are expressed as optical density (OD) at $\lambda=490 \mathrm{~nm}$. Each result represents the mean \pm S.D. of five experimental determinations.

\subsection{Determination of $R O S$}

Determination of ROS was performed by using the fluorescent probe DCFH-DA, as previously described [26]. Briefly, $100 \mu \mathrm{L}$ of $100 \mu \mathrm{M}$ DCFH-DA, dissolved in $100 \%$ methanol, was added to the cellular medium, and cells were incubated at $37^{\circ} \mathrm{C}$ for 30 minutes. After incubation, cells were lysed and centrifuged at $10,000 \times g$ for $10 \mathrm{~min}$. The fluorescence (corresponding to oxidized DCF) was monitored spectrofluorometrically $\left(\lambda_{\mathrm{ex}}=488 \mathrm{~nm} ; \lambda_{\mathrm{em}}=525 \mathrm{~nm}\right)$, using an F-2000 spectrofluorimeter (Hitachi, Tokyo, Japan) and results were expressed as Fluorescence Intensity (F.I.) $\times 1 \times 10^{6} / \mathrm{mg}$ protein. Total protein content in each sample was evaluated according to Lowry et al. [27].

\subsection{Statistical Analysis}

One-way analysis of variance (ANOVA) followed by Bonferroni's $t$ test was performed in order to estimate significant differences among samples. Data were reported as mean values \pm S.D. and differences between groups were considered to be significant at $p<0.005$. 


\section{Conclusions}

Results reported in the present study demostrate that the aqueous extract of Momordica foetida Schumach. et Thonn. has antioxidant activity that can be ascribed to its high content in phenolic and flavonoid compounds. Moreover it is also able to inhibit adipogenesis of hMSC, probably due to its anti-radical activity. These data confirm the therapeutic uses of Momordica foetida Schumach. et Thonn. aqueous extract and also suggest that it might be a useful tool in preventing metabolic syndrome.

\section{Acknowledgments}

The authors thank Mike Wilkinson for proofreading the manuscript.

\section{Conflict of Interest}

The authors declare no conflict of interest.

\section{References}

1. Oloyede, O.I.; Aluko, O.M. Determination of Antioxidant Potential of Momordica Foetida Leaf Extract on Tissue Homogenate. Sci. Med. Clin. Trials 2012, 2012, 1-4.

2. Hakizamungu, E.; Vanpuyvelde, L.; Wery, M. Screening of Rwandese Medicinal-Plants for Anti-Trichomonas Activity. J. Ethnopharmacol. 1992, 36, 143-146.

3. Froelich, S.; Onegi, B.; Kakooko, A.; Siems, K.; Schubert, C.; Jenett-Siems, K. Plants traditionally used against malaria: Phytochemical and pharmacological investigation of Momordica foetida. Braz. J. Pharm. 2007, 17, 1-7.

4. Oishi, Y.; Sakamoto, T.; Udagawa, H.; Taniguchi, H.; Kobayashi-Hattori, K.; Ozawa, Y.; Takita, T. Inhibition of increases in blood glucose and serum neutral fat by Momordica charantia saponin fraction. Biosci. Biotechnol. Biochem. 2007, 71, 735-740.

5. Golbidi, S.; Mesdaghinia, A.; Laher, I. Exercise in the metabolic syndrome. Oxid. Med. Cell. Longev. 2012, 2012, 349710.

6. Bray, G.A. A concise review on the therapeutics of obesity. Nutrition 2000, 16, 953-960.

7. Grattagliano, I.; Palmieri, V.O.; Portincasa, P.; Moschetta, A.; Palasciano, G. Oxidative stress-induced risk factors associated with the metabolic syndrome: A unifying hypothesis. J. Nutr. Biochem. 2008, 19, 491-504.

8. Imhoff, B.R.; Hansen, J.M. Differential redox potential profiles during adipogenesis and osteogenesis. Cell. Mol. Biol. Lett. 2011, 16, 149-161.

9. Lee, H.; Lee, Y.J.; Choi, H.; Ko, E.H.; Kim, J.W. Reactive oxygen species facilitate adipocyte differentiation by accelerating mitotic clonal expansion. J. Biol. Chem. 2009, 284, 10601-10609.

10. Chaudhari, P.; Ye, Z.; Jang, Y.Y. Roles of Reactive Oxygen Species in the Fate of Stem Cells. Antioxid. Redox Signal. 2012, doi:10.1089/ars.2012.4963.

11. Kanda, Y.; Hinata, T.; Kang, S.W.; Watanabe, Y. Reactive oxygen species mediate adipocyte differentiation in mesenchymal stem cells. Life Sci. 2011, 89, 250-258.

12. Vigilanza, P.; Aquilano, K.; Baldelli, S.; Rotilio, G.; Ciriolo, M.R. Modulation of intracellular glutathione affects adipogenesis in 3T3-L1 cells. J. Cell. Physiol. 2011, 226, 2016-2024. 
13. Barbagallo, I.; Vanella, A.; Peterson, S.J.; Kim, D.H.; Tibullo, D.; Giallongo, C.; Vanella, L.; Parrinello, N.; Palumbo, G.A.; di Raimondo, F.; et al. Overexpression of heme oxygenase-1 increases human osteoblast stem cell differentiation. J. Bone Miner. Metab. 2010, 28, 276-288.

14. Vanella, L.; Kim, D.H.; Asprinio, D.; Peterson, S.J.; Barbagallo, I.; Vanella, A.; Goldstein, D.; Ikehara, S.; Kappas, A.; Abraham, N.G. HO-1 expression increases mesenchymal stem cell-derived osteoblasts but decreases adipocyte lineage. Bone 2010, 46, 236-243.

15. Higuchi, M.; Dusting, G.J.; Peshavariya, H.; Jiang, F.; Hsiao, S.T.; Chan, E.C.; Liu, G.S. Differentiation of Human Adipose-Derived Stem Cells into Fat Involves Reactive Oxygen Species and Forkhead Box O1 Mediated Upregulation of Antioxidant Enzymes. Stem Cells Dev. 2013, 22, 878-88.

16. Furukawa, S.; Fujita, T.; Shimabukuro, M.; Iwaki, M.; Yamada, Y.; Nakajima, Y.; Nakayama, O.; Makishima, M.; Matsuda, M.; Shimomura, I. Increased oxidative stress in obesity and its impact on metabolic syndrome. J. Clin. Invest. 2004, 114, 1752-1761.

17. Xu, H.; Barnes, G.T.; Yang, Q.; Tan, G.; Yang, D.; Chou, C.J.; Sole, J.; Nichols, A.; Ross, J.S.; Tartaglia, L.A.; et al. Chronic inflammation in fat plays a crucial role in the development of obesity-related insulin resistance. J. Clin. Invest. 2003, 112, 1821-1830.

18. Da Silva Meirelles, L.; Caplan, A.I.; Nardi, N.B. In search of the in vivo identity of mesenchymal stem cells. Stem Cells 2008, 26, 2287-2299.

19. Crisan, M.; Yap, S.; Casteilla, L.; Chen, C.W.; Corselli, M.; Park, T.S.; Andriolo, G.; Sun, B.; Zheng, B.; Zhang, L.; et al. A perivascular origin for mesenchymal stem cells in multiple human organs. Cell Stem Cell 2008, 3, 301-313.

20. Caplan, A.I. All MSCs are pericytes? Cell Stem Cell 2008, 3, 229-230.

21. LeBel, C.P.; Ali, S.F.; McKee, M.; Bondy, S.C. Organometal-induced increases in oxygen reactive species: The potential of $2^{\prime}, 7^{\prime}$-dichlorofluorescin diacetate as an index of neurotoxic damage. Toxicol. Appl. Pharmacol. 1990, 104, 17-24.

22. Ballard, T.S.; Mallikarjunan, P.; Zhou, K.Q.; O'Keefe, S. Microwave-assisted extraction of phenolic antioxidant compounds from peanut skins. Food Chem. 2010, 120, 1185-1192.

23. Jia, Z.; Tang, M.; Wu, J. The determination of flavonoid contents in mulberry and their scavenging effects on superoxide radicals. Food Chem. 1999, 64, 555-559.

24. Acquaviva, R.; Menichini, F.; Ragusa, S.; Genovese, C.; Amodeo, A.; Tundis, R.; Loizzo, M.R.; Iauk, L. Antimicrobial and antioxidant properties of Betula aetnensis Rafin. (Betulaceae) leaves extract. Nat. Prod. Res. 2013, 27, 475-479.

25. Wolff, S.P. Ferrous Ion Oxidation in Presence of Ferric Ion Indicator Xylenol Orange for Measurement of Hydroperoxides. Method Enzymol. 1994, 233, 182-189.

26. Acquaviva, R.; di Giacomo, C.; Sorrenti, V.; Galvano, F.; Santangelo, R.; Cardile, V.; Gangia, S.; D’Orazio, N.; Abraham, N.G.; Vanella, L. Antiproliferative effect of oleuropein in prostate cell lines. Int. J. Oncol. 2012, 41, 31-38.

27. Lowry, O.H.; Rosebrough, N.J.; Farr, A.L.; Randall, R.J. Protein measurement with the Folin phenol reagent. J. Biol. Chem. 1951, 193, 265-275.

Sample Availability: Samples of the compounds are available from the authors.

(C) 2013 by the authors; licensee MDPI, Basel, Switzerland. This article is an open access article distributed under the terms and conditions of the Creative Commons Attribution license (http://creativecommons.org/licenses/by/3.0/). 